\title{
Title: Manyoka: Is It Vital or Fatal to Human Life?
}

\author{
Qurratulain Nasiruddin* \\ Medical Anthropology, University College, London
}

Submission: April 10, 2018; Published: July 06, 2018

*Corresponding author: Qurratulain Nasiruddin, Aga Khan University-Institute for the Studies of Muslim Civilisations, Medical Anthropology, University College London, United Kingdom, Tel: +447721612677; Email: anny.todai@gmail.com

\begin{abstract}
The countries and societies are under immense burden of communicable and non-communicable disease. Following, Millennium Developmental Goals now signatory countries are focusing on Sustainable Developmental Goals. However, all these efforts and resources do not always give the desires outcomes because they tend to give less attention to their people.Accepting the fact that people differ in their attitudes and behaviours, how a universal treatment regime can benefit each society? Here, comes the need of exploring and understanding the ways diseases-as common as diarrhoea- are understood differently in different societies. Medical Anthropology can be of great help in solving this matrix of diversity of interpretations and can offer solutions to health problems which are community-centred and more acceptable.

Keywords: Medical anthropology;Pollution theory; Mozambique, Diarrhoea;Culture;Health;Social values; Mannyoka, Manikans, Nyoka; Illness; Manica Community;Mortality rate; Menstruation; Moulding; Vaccine; Sanitation

Abbreviations: MCA: Child and Adolescent health; WSH: Water Sanitation Health; FOS: Food Safety and Zoonosis; IVR: Initiative for Vaccine Research
\end{abstract}

\section{Introduction}

The arrival of modern medical sciences and new inventions in the field of health has immensely benefitted human beings all over the world. But despite these successes in the field of sciences, there are communities in parts of the world who are reluctant to maintain their well-being through modern medicine. Their approach towards health is not just a matter of concern in the continuum of health and illness; rather it is entangled with their whole system of ethos and ideals. This paper explores the approach of the Manica community in central Mozambique towards the health issues of diarrhoea. Following, this paper discusses:

a. The burden of diarrhoea in Mozambique and the World Health Organization's (WHO) initiatives to eradicate this problem.

b. 'Beliefs' as an eccentric component to modern medicine and an integral component in world-view of a community; and

c. The pollution theory amongst Manicans. All these points of discussion highlight a thick-description of understanding why a certain disease prevail in a community? It also suggests that the success of health regimes rests in understanding and taking anthropological approaches to incorporate the local beliefs and practices of a community where health and illnesses are knitted in the social fabric of world views and cultural beliefs.

Diarrhoea: A Global and a Local Concern to the Manica Community

Each year around 138 out of 1000 children die out of diarrhoea[1]. This is ranked as the second leading cause of death in children less than 5 years of age all over the world. In Mozambique, the mortality rate among children under age of 5 years who die because of diarrhoea exceeds 17000[2]. These statistics rank Mozambique on number 28thamongst all other countries of the world with high infant mortality rate because of the burden of diarrhoea. Thus, diarrhoea is a significant health issue for the country.

To resolve the issue, several projects from WHO were implemented, for example Maternal, New born, Child and Adolescent health (MCA), Water Sanitation Health (WSH), Food Safety and Zoonosis (FOS) and Initiative for Vaccine Research (IVR). In order to eliminate the diseases from the population of Mozambique, these all projects focused on separate causes and risk factors. Where some projects aim to prevent epidemics by improving health practices of the population; other projects were meant to avoid epidemics on secondary or tertiary level of health care. Some common aspects of the disease taken care by 
these projects included physiology, environment, pathology or the social-behaviour of the population. Nonetheless, the sociocultural beliefs and value systems of the population remained missing.

Often, biomedicine rely more on facts and knowledge where local beliefs and the world-view of a community regarding a disease are ignored. Beliefs are convention ideas and more often as antonym to advancement and threat to biomedicine[3]. Even if knowledge of medical science is built upon empirical experiments and hardly allows any beliefs to interplay in health care systems; one cannot undermine that beliefs are strongly held convictions and influence individual's health choices and behaviours, directly or indirectly. Thus, the healthcare projects merely relying on facts and statistics tend to face rejection from a community whose understanding of certain health problem roots in their cultural beliefs prior any scientific justification.

\section{The case of the Manika community}

In 1994, three anthropologists- Green, Jurg and Djedjedecided to understand the increasing cases of neonatal and child mortalities and possible explanations for the failure of certain health projects in reducing diarrhoea cases in Mozambique. They found out that, for Manicans, mannyoka (diarrhoea) is a process in human body where all impurities are flushed out by nyoka (a snake) in the stomach of the sufferer body. Nyoka is perceived to be the guardian and protector of human body and, so its name means 'guardian of bodily purity'. Thus, nyoka demands a body free of all impurities and contaminations. If nyoka finds the body, where it inhabits, it starts reacting by flushing the impurities out in form of diarrhoea.

Manicans believe that every human being is naturally born with a nyoka in their body which stays in stomach until death. It cannot be seen by any means but, it is helpful in cleansing the body by means of menstruation or diarrhoea. The movement of nyoka causes cramps and contractions in the body. Bio-medical researchers may define nyoka as the intestinal worms that occasionally appear in faeces but, it is not the same[4].The body as understood by Manicans get impure by certain activities. Such activities enlist ingestion of spoil food, drinking contaminated water or involvement of oneself in sexual intercourse while the female partner is menstruating. For menstruation, it is believed that menstrual blood is a polluted fluid accumulated in a woman's body[5]. Therefore, during menstruation, her nyoka twists and turns to expel the impure fluid which cause her dysmenorrhoea (discomfort during menstruation). Also, if a man performs sexual activity with a menstruating woman, he will be contaminated by impure blood of the woman which will cause nyoka khundu (a sexually transmitted disease). Similar concepts are also part of other communities such as Kalasha in Pakistan, Pangia of the New Guinea highlands, Balinese in Indonesia and the Native Americans Yupik of central Alaska.
Their concept of purity generates 'pollution theory' which is a well-versed conceptual framework in social anthropology.

\section{The Pollution Theory}

In 1966, Mary Douglas postulates the theory of pollution and the danger in relation to its significance in describing world-order in some cultures[6]. Through her field-studies, she concluded that, in some cultures, certain elements of a human body are necessarily considered polluted. Here, the term 'pollution' is related to the power which may contaminate or disorder the usual system of culture. For example, an intact body is considered pure whereas, a wound or an injury makes the body vulnerable to be impure by entry of external agents in the body. The reasoning of impurity and its agents varies in every culture. Where these narratives sound more like stories, they are social and cultural constructs which have maintained decorum and social norms in the community for centuries.

In scientific medicine, diarrhoea is defined as passage of three or more loose stools per day caused a variety of bacterial, viral and parasitic organisms[7]. Diarrhoea is also counted among infections spread through contaminated food or drinking-water, or from a person to another person as a result of poor hygiene. One may observe that the concept of purity is implied in scientific medicine as well. Nevertheless, the reasoning and context differs extensively. For instance, contamination may be conceived in natural terms as dirt, or it may mean the pollution of sin or evil spells in mystical terms. Contrastingly, the Manika community provides different explanation for diarrhoea describing a unique kind of diarrhoea. One of the kinds considers sexual relation of either parent of the child outside marriage as the reason. Another kind is caused when mother of the child steps on breast milk (considered to be impure) of a woman who previously had a miscarriage. There is one more kind of diarrhoea which is a result of failure to perform funeral rituals for a family member by parents of the diseased child. Some Mozambicans think that the failure to offer funeral prayers is 'a sign of being too modern' against which, god/gods punish in form of diseases such as diarrhoea.

The diversity of reasons for the same disease invites discussions from two lenses. Firstly, the cosmological orientation of Manicans lies in the concept of purification. Accordingly, cultural rituals appear as a form of exercising powers to remove dirt or impurities from one's body, as impurities are perceived threat to their social order [8]. This is a clear indication that health and well-being of Manicans is not separated from social institutions in their society. In order to be well, Manicansmust abide by their social norms. Therefore, a medicine or an intervention dealing with diarrhoea in isolation cannot be helpful.

Secondly, the perspective of the community towards health and life varies from that of the medical sciences. One may 
not doubt that modern medicine aims to work for the health benefits of human beings. As mentioned in United National Millennium Declaration report [9], the United Nations target to reduce maternal mortality by three quarters, and under-five child mortality by two thirds, of their current mortality rates by 2015.In order to achieve the target, several projects on regional, national and international levels have been established. One may argue that the whole notion of medical care and the development of medicine are based on the ideals of human dignity and worth of individual life. Keeping this ideal in mind medical science encourages exploring all avenues to facilitate human's healthy living. Although cultures also believe in human dignity but the ideal which they promote regarding health is different in comparison to those of medical sciences. For example, medical science is concerned with the physical survival of individuals whereas cultures stresses upon living in accordance to their values and virtuous ideals. Even sometimes these ideals are more important than simply living alive. In case of Manican community 'pure living' is so significant that it is worth to endanger one's life to attain purity, i.e., by not curing diarrhoea because it makes one pure.

\section{Conclusion}

Health is a social structure that operates in relation to other social structures such as poverty, governance, gender, values, beliefs, world-views and religion. The anthropological practices and approaches towards health issues is one of the best ways to understand health as social structure and its relationship with other social realities. Though biomedicine often supersedes importance of culture and values in medical hegemony due to its empiricism. There are still societies such as Manika who operate in the wide web of social and cultural beliefs.There is no argument against the significance of medicines and advance technology to treat an ailment.

However, the limitation is that biomedicine can only treat a disease whereas anthropologist emphasize on 'healing people'.
The difference in the outlook of the two can make it difficult to combat global health issues. Thus, a harmony between the two can be an opportunity. In the case of Manika, for example, the focus of the programmes could move from "elimination of diarrhoea" to "decreasing neonatal and children death due to dehydration caused due to diarrhoea". Possibly, medical regimes and programmes can gain success by moulding and shaping health interventions according to the need and understanding of the targeted community.Thus, health behaviours and attitudes are informed and reflective of values and beliefs of people. Any global health program cannot produce desire result without understanding the complete nexus of these social institutions, in the heart of which lies health.

\section{References}

1. (2009) Public Health and the Environment. Country Profile of Environmental Burden of Disease. World Health Organization, Geneva, Switzerland.

2. Ibid.

3. Pelto PJ, Pelto GH (1997) Studying Knowledge, Culture, and Behavior in Applied Medical Anthropology. Medical Anthropology Quarterly 11(2): 147-163.

4. Ibid p. 10

5. Green EC, Jurg A, Djedje A (1994) The Snake in the Stomach: Child Diarrhea in Central Mozambique. Medical Anthropology Quarterly 8(1): 4-24.

6. Douglas M (1966) Power and Dangers. Purity and Danger: An Analysis of the Concepts of Pollution and Taboo. Routledge classics, London, UK.

7. Fact sheet $N^{\circ} 330$ Diarrhoeal disease (2009) Media Center, The World Health Organizations, Geneva, Switzerland.

8. Green EC, Jurg A, Djedje A (1994) The Snake in the Stomach: Child Diarrhea in Central Mozambique. Medical Anthropology Quarterly $8(1): 48$

9. United Nations Millennium Declaration (2000) Agenda item 60 (b) 0055951. The General Assembly, United Nations p. 5.

\section{Your next submission with Juniper Publishers} will reach you the below assets

- Quality Editorial service

- Swift Peer Review

- Reprints availability

- E-prints Service

- Manuscript Podcast for convenient understanding

- Global attainment for your research

- Manuscript accessibility in different formats

( Pdf, E-pub, Full Text, Audio)

- Unceasing customer service

Track the below URL for one-step submission https://juniperpublishers.com/online-submission.php 